\title{
Middle Lands in Friuli Venezia Giulia. Research by Design and Towards Action
}

\author{
Elena Marchigiani ${ }^{(\bowtie)}$ \\ Department of Engineering and Architecture, University of Trieste, Trieste, Italy \\ emarchigiani@units.it
}

\begin{abstract}
In the Italian Region Friuli Venezia Giulia, 71\% of the Municipalities count less than 5,000 inhabitants, with a stop in population growth and an increase of aging trends. In the frame of the cohesion policies (National Strategy for Inner Areas - SNAI), three Project Areas were identified in the mountain sector. However, the presence of middle lands is even more pervasive. This term stands for marginalised contexts, outside those identified by the SNAI; they are dotted by natural and rural landscapes, small urban centres, and the peripheries of medium cities. Here the number of inhabitants and the functioning of services still hold on, economic crisis and abandonment have not reached their climax. Nonetheless, the risk to slip into more serious conditions of fragility is strong.

Since some years, at the University of Trieste, these areas have been the object of Urban Planning Courses. The methodology is that of research by design to support local planning and regional policies. Starting from the characters of marginalised contexts in Friuli Venezia Giulia, this paper presents the outputs of the activities developed in the middle lands along the river Cormor. Through the interaction with the Municipalities involved in the construction of a River Contract, the request to draw the extension of a horse/cycle path offered the opportunity to reflect on how to reconceive economies and services related to slow tourism within a larger planning perspective. Project investigations interpreted Cormor as the spine of a network of ecological services, and new functions were defined for existing collective facilities. The research is in progress, and more contexts will be studied within Friuli Venezia Giulia SNAI's areas. In view of the next season of EU cohesion policies, the closing paragraph questions the definition of place-based development strategies for marginalised territories, and the need to go beyond spatial perimeters centred on abstract statistical indicators and accessibility parameters.
\end{abstract}

Keywords: Friuli Venezia Giulia $\cdot$ Middle lands $\cdot$ Local development

\section{Introduction}

\subsection{A Growing National Debate}

In Italy, over the last years, there has been a rekindling of debate on territorial representations as a support to economic programs and cohesion policies [1, 2]. The start in 2014 of the National Strategy for Inner Areas (SNAI) was a turning point [3]. The classification of the Italian territory on the basis of the different degrees of accessibility 
to urban poles and services directed funding on some target areas in the most serious conditions of depopulation, economic crisis, hydrogeological and seismic risks ${ }^{1}$. This has opened up the possibility to start a new phase of development policies, and today SNAI's results offer inputs to further thought and action.

In the view of the next 2021-2027 EU programs, planning reflection is focusing on the variety of peripheral situations that characterise large parts of Italian urbanised contexts: in addition to the fragile and abandoned territories that are already included in the SNAI, the reflection also concentrates on the outskirts of large and medium urban centres, as well as on the variety of in-between landscapes made of disconnected aggregates of rural areas and small towns ${ }^{2}$. What emerges is a geography of different marginalised areas, punctuating the north and south of the Country, the mountains and the plains; they share problems of economic and/or demographic shrinkage, and the need to deeply reorganise the offer of basic equipment for social and health care, education and mobility.

However critical this representation of Italy may be, it also suggests a radical shift in development perspectives for both marginalised contexts and the whole Country. Extending and refining SNAI's approach, while putting aside policies based on a mere defence and homologation of 'slower' contexts to the (few) competitive urban areas, can be a way to give a voice and a future to many peripheral situations. The reference is to place-based projects, built together with local populations, and aimed at reactivating existing (and often hidden) resources and social-economic initiatives. However, localism is not enough. A new course of public-directed policies, addressing public and private investment, and referring to an urban strategy built on national and regional scales, is strongly needed [5-7].

\subsection{Marginalised Areas in Friuli Venezia Giulia}

Within a reflection on marginalised areas, the case of the Italian region Friuli Venezia Giulia is significant. Here $71 \%$ of the Municipalities count less than 5,000 inhabitants, with an overall standstill of population and a growth of aging trends; there is only one medium-sized city (Trieste, 204,338 inhabitants), and three small capital cities (Gorizia, 34,411; Pordenone 51,139; Udine, 99,518 inhabitants) [8]. Three SNAI's Project Areas have been recognised in the mountain sector: Dolomiti Friulane, Alta Carnia, Val Canale - Canal del Ferro (43 Municipalities and about 58,000 inhabitants in total, nearly $4.8 \%$ of the overall regional population) $[9]^{3}$.

\footnotetext{
${ }^{1}$ On the basis of the travel time by car to the nearest urban/intermunicipal pole of services, SNAI classifies as "inner areas": "intermediate" (20-40 min), "peripheral" (40-75 min), "ultra-peripheral" (over $75 \mathrm{~min}$ ) territories. They cover $51.7 \%$ of Italian Municipalities, $22.4 \%$ of national population and nearly $60 \%$ of the Country surface. By 2018, 72 target areas were selected; they cover 1,071 Municipalities (26\% of territories classified as inner areas) [4].

${ }^{2}$ The building of atlases and debate on marginalised areas are currently at the core of research, seminars and conferences developed by the Italian Society of Planners (sIU; a technical group was established in 2019), the Italian Institute of Planning (INU), the National Research Council of Italy (CNR-IRISS), and many Italian Universities (among the others, Politecnico of Milano, Politecnico of Torino, IUAV of Venezia, Università Federico II of Napoli, Università di Camerino).

${ }^{3}$ By 2020, only one of the Strategies for the sNAI's areas (Alta Carnia) was approved by the National Committee for Inner Areas, shile the other two are still under signature by the Ministries.
} 
If the coverage of SNAI's areas is quite relevant, the presence of middle lands is no less extensive. This term refers to contexts that, while pervasive, do not fall within the parameters and perimeters established for the SNAI's most marginal territories. In the middle lands, the number of inhabitants and the distribution of services still hold on (albeit with difficulty), the situations of economic crisis and abandonment are still limited, ecological, landscape and historical assets are often consistent, and entrepreneurial culture has not yet disappeared. Nonetheless, the increase of environmental and social and economic challenges, and the difficulties of small Municipalities to coordinate action and resources, put these contexts at the risk of slipping into more serious conditions of marginality. Today, the middle lands and the inner areas of Friuli Venezia Giulia jointly suffer from the lack of a regional vision, helping reactivate their development potentials. It is therefore no coincidence that in the SNAI's areas the expenditure of the available European, national and regional funds shows significant delays, nor that the access to specific funding remains highly uncertain for the middle lands of this region.

Since some years, at the University of Trieste, the strategic role that marginalised areas can play in spatial plans - both at the regional and the intermunicipal levels - has been the object of project investigations. The methodology is that of research by design to support policy and action. In the frame of the teaching activities of the Master Course in Architecture, regional contexts are chosen on the basis of the opportunity to work with local actors, in order to help them build development scenarios which are strongly embedded in local resources. This paper presents the outputs of the first investigations carried out in the middle lands along the river Cormor. The second paragraph describes the main features of the study area and the invitation to reflect on new interpretative approaches offered by the interaction with the Municipalities involved in the construction of a River Contract. The third section explains how the local stakeholders' request to draw the extension of a horse/cycle path was specifically translated into an opportunity to reframe economies and services related to slow tourism within a larger planning perspective. In this perspective, the Cormor was read as the spine of a network of ecological services, and new functions were defined for existing collective equipment. The research is in progress, and more contexts will be studied within Friuli Venezia Giulia SNAI's areas. In view of the next season of EU cohesion policies, the closing paragraph questions the definition of place-based development strategies for marginalised territories, and the need to go beyond spatial perimeters centred on abstract statistical indicators and accessibility parameters.

\section{The Middle Lands Along the River Cormor}

Working on the middle lands along the river Cormor provided insights into territorial conditions that recur in Friuli Venezia Giulia [10] ${ }^{4}$. In this region, many urban centres stand nearby the system of rivers stretching from the mountains to the sea. The focus of

\footnotetext{
${ }^{4}$ The reference is to the Urban Planning and Design Studio (academic year 2018-2019), at the fourth year of Architecture, coordinated by Elena Marchigiani, with Paola Cigalotto and Andrea Peraz.
} 
the University activities was on the sequence of urbanised spaces, including the small centres along the river Cormor, and the western peripheries of the middle-sized city of Udine $^{5}$. These areas were selected in order to cover a significant sample of intertwined river and urban landscapes: from the northern foothill sector, where the Cormor runs in the middle of the reliefs topped by ancient villages; to the 'dry plain', where Udine conurbation lay, and the minor water network is mainly underground; to the southern 'wet plain', where the water comes again to the surface, and the urbanization becomes more scattered (Fig. 1).
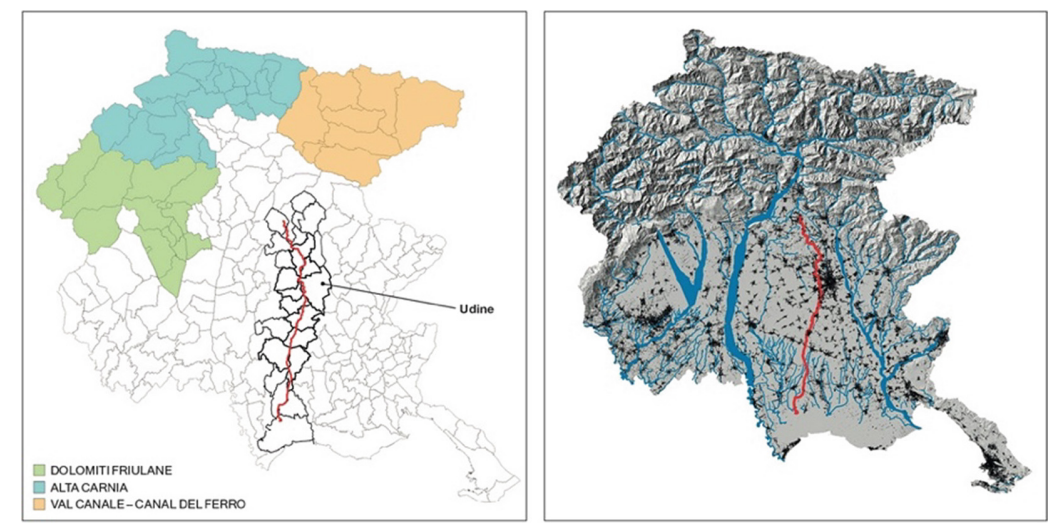

Fig. 1. Friuli Venezia Giulia. On the left, the SNAI's Project Areas and the Cormor middle lands; on the right, the settlements framework, the main watercourses, and the orography. In red, the river Cormor (SOURCE: L. Di Giusto)

\subsection{Edge Territories Back at the Centre}

Despite the presence of areas of environmental interest, over time, the weakening of relationship between the river landscapes and the neighbouring urban centres has contributed to relegate Cormor to a marginal position within the overall functioning and use of these middle lands. At a first glance, no exceptional landscapes, nor outstanding tourist and cultural attractors can be recognised. The minimal and ordinary elements of spatial identity and rural production suffer from the crisis of the social and economic conditions that, in the past, ensured their construction and management. Standing on the edge of the city and the countryside, of the water and the land, these counter-spaces of the contemporary urbanisation risk being reductively interpreted as places that don't matter, where abandonment and degradation are unavoidable [11].

However, these interpretative drifts can be eluded by taking a different approach. The first move is to re-centralise the margin [6]. By making our glance more attentive, we have to search for the local conditions where to graft trajectories of internal

\footnotetext{
5 The investigation covered 11 Municipalities in the former province of Udine (from Tricesimo at the north, to Castions di Strada at the south), counting about 171,000 inhabitants.
} 
metamorphosis. In this perspective, the relationship with the river can once again become an opportunity to answer the contemporary demands for a better quality of life, and for a 'slower', more sustainable and endogenous social and economic growth [12, 13].

\subsection{The River Contract as an Opportunity}

The opportunity to test this approach on the Cormor middle lands was given by the collaboration with local stakeholders ${ }^{6}$. Since the early 2000 s, a number of Municipalities along the river have started to jointly reflect on the sustainable management of water resources and the settlement of new economic activities. Thanks to European cooperation funds, they succeeded in equipping the northern part of a horse and cycle track (Ippovia del Cormor). With the Valle del Cormor citizens' Association, the Municipalities are now engaged in the definition of a River Contract: a largescale and long-term strategic and planning tool, where environmental issues combine with those of local development.

The process towards the River Cormor Contract was fostered by the adhesion of the Friuli Venezia Giulia Region to these initiatives (in 2016), and by the perspective of future funds (that, however, have not yet been programmed) ${ }^{7}$. In 2017 , the Valle del Cormor Association organised participatory activities with local communities. The definition of the Document of Intents for the River Contract started in May 2018. The actions developed with the University of Trieste strongly interacted with this process. In April 2019 the signature of the Document of Intents started, under the coordination of the Municipality of Tricesimo, with the involvement of the Friuli Venezia Giulia Region, the Reclamation of the Friuli Plain Consortium, and the Valle del Cormor Association. The objectives set by the Document cover different fields of action. They do not only consist in environmental protection, the prevention of hydrogeological risk, the reduction of water pollution due to urban and agricultural activities. They also deal with the tourist development of these territories, whose location in the proximity of important European cycle routes offers unprecedented opportunities (the reference is to the Alpe Adria cross-border itinerary $)^{8}$.

The stakeholders' request to design the extension to the Adriatic Sea of the horse and cycle track along the river gave the University a chance to reframe the issue of tourism in an integrated planning perspective, and to imagine the accessibility to the watercourse as a driver for new economies and services spreading their effects on larger territories.

\footnotetext{
${ }^{6}$ The teaching and research activities developed by the University of Trieste were organised in the frame of an agreement between the Department of Engineering and Architecture, the Municipality of Tricesimo, and the Valle del Cormor Association.

7 The Regional Law no. 11/2015 defined and structured the process of negotiated planning for the River Contracts; with the resolution of the Regional Council no. 1448, 28.07.2016, Friuli Venezia Giulia formally adhered to the National Charter of River Contracts, launching activities aimed at promoting and supporting them on the regional territory [14].

${ }^{8}$ In the Regional Landscape Plan approved in 2018, the completion of the Ippovia del Cormor is part of the project for a regional slow mobility network [15].
} 


\section{Project-Oriented and Shared Representations}

Teaching and research by design activities were addressed to draw representations and project inputs that could help local actors build deeper reflection on future policies and spatial interventions. The prompt was to read the river not as a trivial back of cities and rural sites, but as the spine of a new system of ecological services, able to put into play a rich estate of often underused public facilities and housing settlements, and to redefine cycle tourism in relation to the particular sensitivity and lifestyles of the Cormor middle lands.

During this process, professors and students were accompanied by representatives of the Valle del Cormor Association and of the Municipalities adhering to the River Contract. We started by combining the analysis of the current planning tools with visits to the study areas, where we talked to technicians and politicians, listened to inhabitants, observed and reflected in places. The discussion with our partners of intermediate results further prompted to synthesise ideas into new representations of existing resources and of their enhancement opportunities.

We were convinced that co-building explorations of locally rooted potentials for economic and social redevelopment had to be an essential ingredient of our contribution to the implementation of the River Contract. In this view, we started from recognising the functions and values of the waterway ecosystem, with the aim to take the places where they materialise as the main components of a new spatial system, in which the development of green and blue networks, of new tourist activities, and the reuse of existing equipment can find a synthesis and mutual interactions.

\subsection{A Complex Ecosystem}

All through the Urban Planning and Design Studio, students and local actors were invited to interpret the river contexts as a complex ecosystem.

In order to safeguard, restore, enhance and manage river landscapes, it is necessary to identify correlations among a multiplicity of material and immaterial processes and elements of the territory [16]. This viewpoint allows to recognise the primary value of the interconnections between the river and the urban settlements, the natural elements, and the evidence of local culture and production.

Building visions for the Cormor landscapes therefore meant focusing on the different functions (and values) that, today, waterways can recover in the fields of: ecology (rivers as excretory systems; natural corridors; areas where to govern hydrogeological fragility); society (rivers as spaces perceived and enjoyed by local communities; common goods; components of equipment addressed to stable and temporary, static and moving populations); economy (rivers as places for sustainable activities, different from intensive production and agricultural exploitation); culture (rivers as gates through which to rediscover and enhance the history and the identity of the territory, and as attractors of new tourist flows). In this way, the focus on the Cormor stream and trail was framed into a more complex spatial system. 


\subsection{Tourism and Well-Being}

The issues of tourism and cycling added further inputs for drawing new representations of the Cormor ecosystem. Specifically, they invited to interpret the river as the component of a network of greenways [17]. Emphasis was put on the many potentials of slow mobility: from favouring the access and enjoyment of 'minor' landscapes; to offering the opportunity to activate circular economies. However, cycling is not only a tourists' practice. In our Country, the growth of seasonal and daily soft mobility is tracing new geographies, that tell how local administrations, stakeholders and enterprises have been able to conceive products and services of particular innovation and excellence, addressed both to tourists and residents [18].

According to these considerations, we invited the students to conceive the greenways as part of the system of collective equipment that already punctuates the Cormor middle lands. Our surveys had in fact shown how the fragility of the territories along the river and of the communities that inhabit them was also connected to a growing lack in the maintenance of public spaces and services; to their inadequacy to the needs of moving and changing populations; to their closure to the contexts and difficult accessibility. Integrated work on the banks of the river and on the edges of urban centres, on the rural spaces and on the leftovers of peri-urban agriculture, was therefore a stimulus to take the project of the cycle route as a prompt to rethink the uses of public facilities and their spatial connections; to regenerate the legacy of urban policies and planning standards that, over time, have built the material quality of welfare and of everyday life (green areas, spaces for mobility, social-assistance and educationalcultural services) [19].

\subsection{Light Infrastructural Projects for Local Development}

The search for places and materials where light infrastructural and re-equipment projects could be grounded forced us to continuously move across different scales. We started from a larger perspective, to draw a master plan holding together the many functions that the Cormor middle lands can play as a whole. In general terms, the horse and cycle itinerary was conceived not as a single path, but as a widespread infrastructure for the slow use of the territory. Design explorations showed the capacity of the cycle route to promote environmental protection and risk management, as well as to attract inhabitants and enterprises through the settlement of new facilities (accommodation and catering equipment, connected to the production, sale and consumption of typical goods; sports events and trails, offering the experience of regional landscapes). The parallel focus on a site-specific scale allowed to articulate the master plan according to different territorial situations. Specifically, three types of spatial 'transects' were recognised, on the basis of the features of the watercourse (channelled or not, above-ground or at a lower level, with natural or artificial banks), the proximity of the cycle way to the river, the combination of urban, rural or natural land uses. This, again, proved the internal variety of the middle lands, and the need to adjust visions and projects to their resources. 

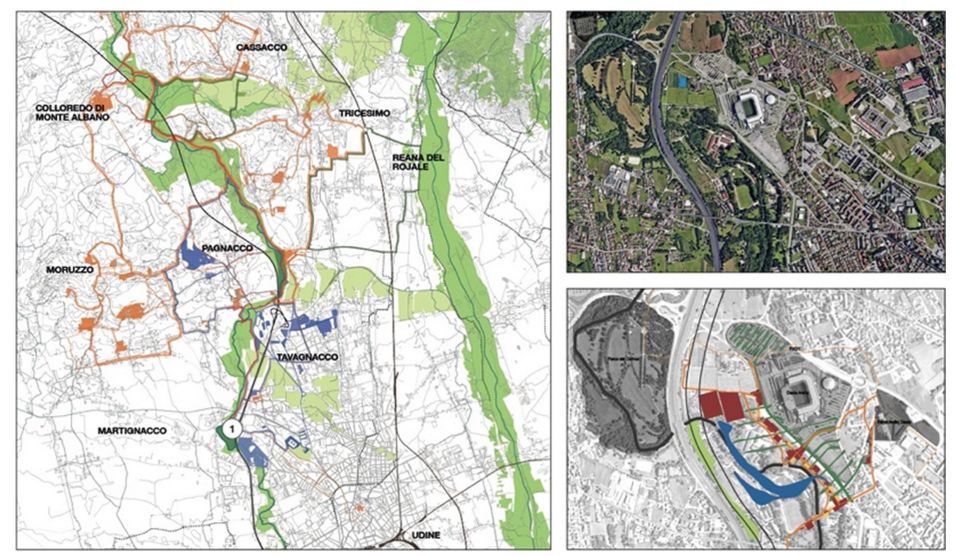

Fig. 2. The northern transect. On the left, the master plan; on the right, the Cormor and the citadel of sports in Udine (no. 1) (SOURCE: P. Barbiani, M. Caiffa, M. Collenz, S. Di Ferro, L. Lauricella, I. Morgera)

In the master plan for the northern transect, cycle itineraries link the main path along the river bank to the rural villages, historic villas and castles on the hills, and to the railway stations of small urban centres. Two main greenways articulate the picture, by overwriting the sequence of crops and areas of landscape interest that, across the plain, connects the rivers Cormor and Torre. When reaching the edges of Udine conurbation, this structure offers the opportunity to tackle the functional and spatial segregation of existing large plots for territorial equipment. Specifically, in the riverbed of the Cormor, new drainage basins, reed beds, and rows of trees are meant to reduce the impacts of the nearby highway. These green infiltrations further extend, to scratch the surface of the paved areas around the citadel of sports. Not far away, along a branch of the cycle path, shared vegetable gardens and areas for market and recreational activities draw a series of public spaces; their articulation helps bridge the gap between the huge scale of the sports complex and the fine grain of the surrounding settlements (Fig. 2).

In the central transect, the cycle route passes from one side to the other of the Cormor. By intercepting and supporting the reuse of 'vague lands', the soft mobility network contributes to the redesign of the fringes of Udine, Pasian di Prato and Campoformido. Like a comb, the bicycle ring road provides a fast connection for tourists and citizens, who can reach the leisure areas along the river by avoiding the busiest radial roads, and safely access the services in the city centre. When crossing the peripheries built by social housing districts and private neighbourhoods, this infrastructure becomes the backbone of a necklace of parks, adding porosity and permeability to urban land. Here, new woods and collective gardens spread transversally to the river, and trigger the regeneration of large urban sectors by connecting existing equipment to new types of services for education and open-air activities, light manufacture and urban agriculture (Fig. 3). 

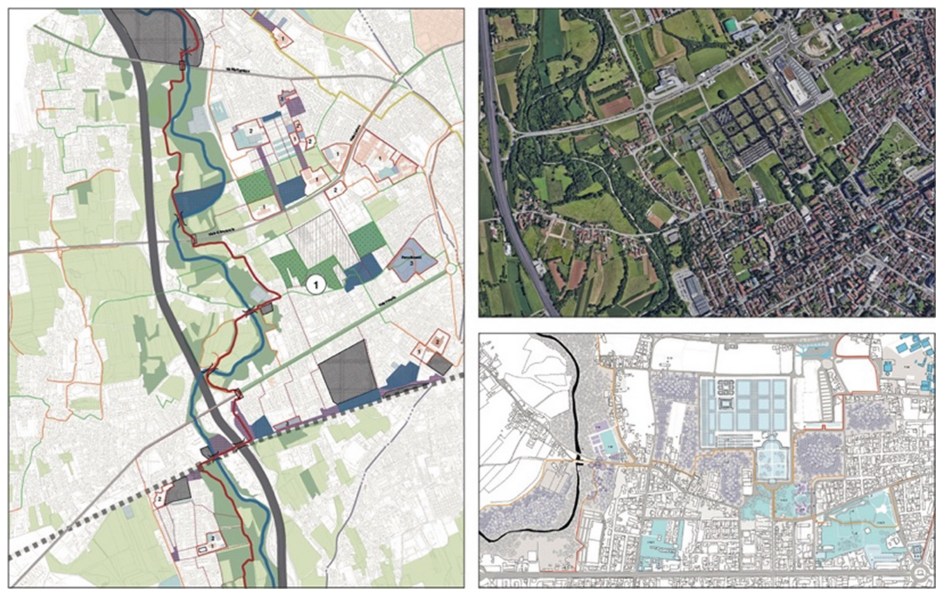

Fig. 3. The central transect. On the left, the master plan; on the right, the Cormor and the new urban woods in the residential peripheries of Udine (no. 1) (SOURCE: G. Bearzotti, G. De Conz, T. Linternone, T. Lippiello, M.T. Manzara, V. Novello, N. Pigat, G. Zei)
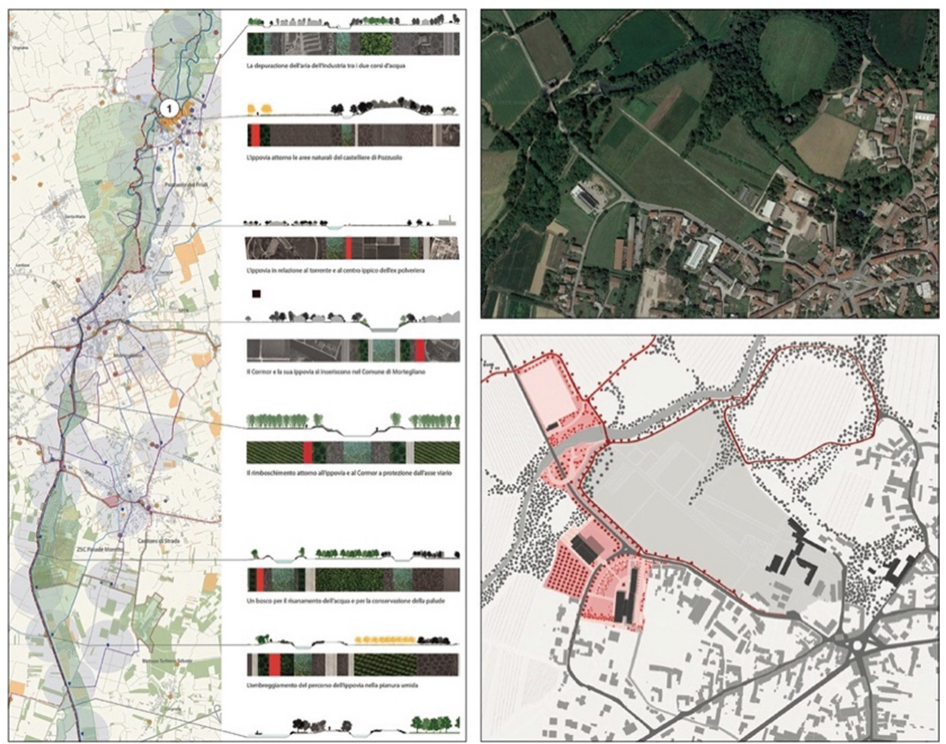

Fig. 4. The southern transect. On the left, the master plan; on the right, the river Cormor and the design inputs for the reuse of the beaches and the spinning mill in Pozzuolo del Friuli (no. 1) (SOURCE: D. Buccino, C. Furlani, S. Maiello, A. Romanzin, G. Tomasin, G. Vallone, F. Zotti, N. Zucchiatti) 
Before reaching the lagoon and the sea, the Cormor relates again to the fine-grain of urbanised contexts and rural lands (Pozzuolo, Mortegliano and Castions di Strada). In this section of the watercourse, the extension of the bike path was a particularly complex design task. In order to identify resources to connect and upgrade, these territories had to be read in braille, through layers and careful examination. However, here more than in the other transects, the project of the cycle route offered the opportunity to demonstrate how slow mobility can help activate circular economies. In the master plan, the cycle itinerary follows the dirt roads next to the Cormor, searching for valuable landscapes and artefacts. New basins along the stream are meant not only to manage the waters and to treat pollution from rural activities, but also to design an extensive landscape project, linking the wetlands that characterise the southern section of the river. Arboriculture and reforestation give thickness and economic function to these environmental connections, that further and capillary radiate in the vegetal rows and hedges along the roads. The cycle itinerary also helps define themes for a selective reuse of abandoned spaces. Old beaches, mills, factories and warehouses, irrigation ditches tell the story of local life and production, by hosting new services and economic activities (from hostels and refreshment areas, to centres for education, research and/or enterprises' innovation) (Fig. 4).

\section{Conclusions in Progress}

The research is still on-going. In the academic year 2019-2020, thanks to interaction with local stakeholders ${ }^{9}$, other study contexts will be chosen in the regional SNAI's areas (Alta Carnia, Val Canale - Canal del Ferro). Here, abandonment and depopulation trends ask for deeper investigation into the topics of economic regeneration (agricultural and manufacturing chains have to be radically rebuilt), environment and landscape protection (hydrogeological problems are strong, and so are the traces of a dramatic 'border history'), actions addressed to attract new and/or returning inhabitants. The work on the Cormor middle lands and the preparatory surveys on the mountain SNAI's contexts therefore trigger further reflection. However, some fundamental issues on planning and development in marginalised areas can already be recognised.

A first issue refers to prosperity, whereas the stimulus is to take a distance from mere economic growth paradigms [20]. Prosperous is a path that takes root in the places (their biographies and delicate metabolisms), and allows inclusive access to territorial resources. The immersion in the Cormor middle lands showed the need to turn to new forms of environmental determinism. This means negotiating the landing on Earth of our policies, by taking the Terrestrial (with its material features and human-non-human processes) as an essential and plural actor of future strategies and projects [21]. Only by putting aside the prevailing of economic determinants and by adopting a more responsible perspective, can we recover the ability to imagine a future of resilience and care for the places we live in.

\footnotetext{
${ }^{9}$ Our next partner, Cramars NGo, is active in the fields of professional education, social innovation and local development; thanks to Eu projects, Cramars is promoting the construction of an Atlas of Friuli mountain areas, and a Pact for local development among institutions, profit and nonprofit organizations, citizens (https://www.coopcramars.it).
} 
A second issue refers to territorial equipment, as a means to enhance liveability conditions, to adapt to growing environmental and climatic changes, and to help reverse economic and demographic trends. In this sense, working in marginalised areas forces to rethink the location and performance of public facilities and planning standards $[22,23]$. In the visions for the Cormor territories, green and blue infrastructures do not only offer the structuring principles of a new ecological project; they also provide a spatial support to the creation of new services and economies, for tourists and inhabitants. Furthermore, these projects invite to question the territorial perimeters that still guide the allocation of cohesion funds, and are mainly based on statistical indicators and quantitative accessibility parameters. These perimeters tend to overwrite the margins of marginalised areas, preventing possible synergies among existing resources, actors and geographies, as well as their capitalisation by regional and local policies.

The ways of making spatialised policies and planning strategies constitutes a third relevant issue. This is precisely the field where it is urgent to start, on a regional scale, territorial laboratories and pilot projects and alliances across levels, actors and sectors of public government/governance. A careful knowledge and working together with local administrations, economic/third sector stakeholders and communities are in fact necessary to ensure that next EU funds and public spending reach higher effectiveness. Instead of projects calls designed on the basis of general and abstract parameters, what the small Municipalities of the marginalised areas ask for are opportunities to aggregate places and subjects around targeted and synergic actions, aimed at feeding medium and long-term visions for sustainable development. These actions necessarily refer to a variety of policies (environment, economy and professional training, welfare and mobility, etc.), whose integration needs a strong public direction, and a profound change in institutional routines (from the national to the regional and local levels).

Finally, the investigation into the Cormor middle lands stimulates reflection on how far a vision for sustainable development can be implemented even without extraordinary financing channels. Due to their often minimal and incremental character, the design inputs this paper describes are not detached from the themes of municipal (or inter-municipal) urban planning. Even though local plans are often meant as simplified frames for public works and private interventions, their task should be to foster the implementation of future scenarios, by setting a coherence among a variety of spatial issues, actions and actors. In this sense, the hope is that the work done with the University can help address the use of local planning procedures and tools towards the anticipation of more complex, largescale and integrated projects. While recurrently called into question by international Urban Agendas, the ordinary planning practice should in fact start referring to a renovated frame of topics and challenges. This certainly requires a strong commitment by the numerous public administrations that today, especially in the most fragile areas of the Country, are wearied by the lack of economic resources and personnel. Nonetheless, such a viewpoint strengthens the belief that reinforcing the collaboration between the energies and knowledge provided 
by the University on the one side, the questions and practices emerging from the territories on the other, can do more than a lot in stimulating collective social and technical innovation.

\section{References}

1. Calafati, A.G. (ed.): Città tra sviluppo e declino. Donzelli, Roma (2014)

2. Munarin, S., Velo, L. (eds.): Italia 1945-2045. Donzelli, Roma (2016)

3. Ministero per la Coesione Territoriale: Strategia nazionale per le Aree interne (2014). http:// old2018.agenziacoesione.gov.it/it/arint. Accessed 02 Jan 2020

4. Lucatelli, S.: Strategia Nazionale Aree Interne: metodo e stato di attuazione (2019). https:// www.forumdisuguaglianzediversita.org/wp-content/uploads/2019/05/Lucatelli_28-maggio2019.pdf. Accessed 02 Jan 2020

5. Forum Diseguaglianze e Diversità: Fifteen Proposals for Social Justice (2019). https://www. forumdisuguaglianzediversita.org/proposte-per-la-giustizia-sociale/fifteen-proposals-forsocial-justice. Accessed 02 Jan 2020

6. De Rossi, A. (ed.): Riabitare l'Italia. Donzelli, Roma (2018)

7. Carrosio, G.: I margini al centro. Donzelli, Roma (2019)

8. Regione Autonoma Friuli Venezia Giulia: Regione in cifre (2018). http://www.regione.fvg. it/rafvg/cms/RAFVG/GEN/statistica/FOGLIA49. Accessed 02 Jan 2020

9. Regione Autonoma Friuli Venezia Giulia: Strategia per le Aree Interne. https://www.regione. fvg.it/rafvg/cms/RAFVG/economia-imprese/montagna/FOGLIA14. Accessed 02 Jan 2020

10. Marchigiani, E., Cigalotto, P.: Terre di mezzo. Percorsi di progetto lungo il torrente Cormor. EUT Edizioni Università di Trieste, Trieste (2019). https://www.openstarts.units.it/handle/ 10077/27778. Accessed 02 Jan 2020

11. Rodríguez-Pose, A.: The revenge of the places that don't matter (and what to do about it). Camb. J. Reg. Econ. Soc. 11(1), 189-209 (2018)

12. Lancerini, E. (ed.): Territori Lenti: contributi per una nuova geografia dei paesaggi abitati italiani. Territorio 34, 9-69 (2005)

13. Nocifora, E., de Salvo, P., Calzati, V. (eds.): Territori lenti e turismo di qualità. Franco Angeli, Milano (2011)

14. Regione Autonoma Friuli Venezia Giulia: Contratti di fiume. https://www.regione.fvg.it/ rafvg/cms/RAFVG/ambiente-territorio/pianificazione-gestione-territorio/FOGLIA213. Accessed 02 Jan 2020

15. Regione Autonoma Friuli Venezia Giulia: Piano Paesaggistico Regionale. http://www. regione.fvg.it/rafvg/cms/RAFVG/ambiente-territorio/pianificazione-gestione-territorio/ FOGLIA21. Accessed 02 Jan 2020

16. Council of Europe: European Landscape Convention (2000)

17. European Greenways Association: Lille Declaration (2000). http://www.aevv-egwa.org/ greenways. Accessed 02 Jan 2020

18. Velo, L.: La bicicletta un nuovo mezzo per la salvaguardia, il riciclo e la valorizzazione della città diffusa veneta. In: AA.VV., Atti della XVIII Conferenza nazionale SIU, Italia '45-'45, pp. 1663-1669. Planum Publisher, Milano (2015)

19. Pasqui, G.: Urbanistica oggi. Piccolo lessico critico. Donzelli, Roma (2017)

20. Jackson, T.: Prosperity Without Growth, 2nd edn. Routledge, London and New York (2017) 
21. Latour, B.: Où atterrir?. Comment s'orienter en politique. Éditions La Découverte, Paris (2017)

22. Gabellini, P.: Le mutazioni dell'urbanistica. Principi, tecniche, competenze. Carocci editore, Roma (2018)

23. Standard, Laboratorio (ed.): Diritti in città. Donzelli, Roma (in press)

Open Access This chapter is licensed under the terms of the Creative Commons Attribution 4.0 International License (http://creativecommons.org/licenses/by/4.0/), which permits use, sharing, adaptation, distribution and reproduction in any medium or format, as long as you give appropriate credit to the original author(s) and the source, provide a link to the Creative Commons license and indicate if changes were made.

The images or other third party material in this chapter are included in the chapter's Creative Commons license, unless indicated otherwise in a credit line to the material. If material is not included in the chapter's Creative Commons license and your intended use is not permitted by statutory regulation or exceeds the permitted use, you will need to obtain permission directly from the copyright holder. 